\title{
The Relationship between Financial Reporting Quality and Investment Efficiency
}

\author{
Qi Chen \\ Business School \\ Sichuan University \\ Chengdu, P. R. China
}

\author{
Shengnan Zheng \\ Business school \\ Sichuan University \\ Chengdu, P. R. China
}

\author{
Wen Mou \\ Business School \\ Sichuan University \\ Chengdu, P. R. China
}

\begin{abstract}
Investment activities is one of the core financial activities in enterprises, and the financial report, which quality is closely related to the investment efficiency, is the window of knowing the management state. This paper, from the implication of financial reporting quality and investment efficiency angle, hackles the effect of the financial reporting quality on the efficiency of investment. The paper also analyzes the internal mechanism of high-quality financial reporting quality govern the inefficient investment in the frame work of the principal-agent theory and information asymmetry theory. Hereby, we can understand the significance of the high-quality financial report and improve the efficiency of investment.
\end{abstract}

Keywords-financial reporting quality; investment efficiency; principal-agent relationship; information asymmetry

\section{INTRODUCTION}

The financial reporting quality refers to the accuracy of the financial report on providing the company's operating information, especially in the cash flow and profitability which is the top concern of the investors. To assess the quality of financial reporting, firstly, we should clear the quality characteristics of financial reporting, that is, what is the criterion for quality evaluation of financial reporting. The most comprehensive researches on the quality characteristics of financial reporting are focused on the conceptual framework of financial accounting which is published by national accounting standards research institutions. Accordingly, this paper argues that the main features of the quality of financial reporting are relevance, reliability, comprehensibility and comparability. Although the study of the quality characteristics of financial reporting has made great achievements, it has not yet reached a unified understanding of how to measure the financial reporting quality quantitatively. At present, the domestic and foreign researchers mainly use three kinds of quality indicators as the substitute variables of the quality of financial report: the quality of earnings, the quality of information disclosed in financial reports and the characteristics of accounting information quality. Dechow and Dichev (2002) argues that the similarity degree between accruals and operating cash flow can reflects the degree of earnings quality and financial reporting quality, and use accruals residuals to measure earnings quality [1]. Peng Shaobin and Huang Yijian (2008), taking listed companies in China as the research object, investigate the relationship between the reliability of accounting information and earnings persistence, and show that the more reliable the accounting information, the higher the sustainability of accounting earnings. Zhou Zhongsheng and Chen Hanwen (2008) take the transparency of information as the substitute variable of the financial report quality, and investigate the relationship between the quality of financial report and the efficiency of resource allocation.

For the efficiency of investment, in the macro field, scholars often use the "the Incremental Capital Output Ratio" to measure the investment efficiency. In the micro-field, investment efficiency means in the case of frictionless market, enterprises should invest a project which net value is positive. Generally, the lack of investment efficiency includes over-investment and under-investment, the former refers to invest a project which net value is negative, and the latter refers to give up a project which net value is positive. This paper mainly uses the definition of investment efficiency based on the micro filed. In general, domestic and foreign scholars measure the investment efficiency through establishing models. Vogt (1994) builds the cross product term of free cash flow and investment opportunity on the basis of FHP model to differentiate over-investment and under-investment [4]. However, this model has some limitations. For example, it cannot be able to measure the extent of over-investment or under-investment and the measure error of Tobin's Q may result in the high sensitivity between investment and cash flow. Richardson (2006) builds an investment expectation model to measure investment efficiency [5]. This model divides the total investment into two parts: maintenance investment and new investment, and the residuals of the new investment can be used as the substitute variable of investment efficiency. In recent years, this model has been used by many Chinese scholars. Wei 
Haiming (2007) uses it to study the relationship between dividends of state-owned enterprises, governance factors and over-investment [6]. Xin Qingquan (2007) uses it to study the relationship between government control, manager pay and investment efficiency [7].

\section{THE INFLUENCE OF FINANCIAL REPORTING QUALITY ON INVESTMENT EFFICIENCY}

\section{A. The International Perspective}

For the current situation of research, foreign scholars mostly research on the relationship between the efficiency of business investment on the basis of principal-agent theory and information asymmetry theory from the perspective of financing constraints and cash sensitivity. Verdi (2006) takes listed US companies as the research objects, and tests the relationship between accounting information and overinvestment or under-investment based on the investment behavior in the perfect market and Tobin's Q. He shows that the quality of accounting information is negatively correlated with over-investment or under-investment, and proves that the high quality financial report information can alleviate the information asymmetry and agency conflict, reduce the financing constraint of the company and improve the investment efficiency [8]. Biddle and Hilary (2006) shows that the quality of financial reporting is significantly negatively correlated with corporate cash sensitivity which takes listed companies in US and Japan as the research object, and this effect is more pronounced when the company is constrained by the financing of the securities market[9]. Gomariz and Ballesta (2014) study the relationship among the quality of accounting information, the maturity of debt and the efficiency of investment by taking the Spanish listed companies as a research sample, and show that accounting information quality and debt maturity have an alternative relationship in improving investment efficiency[10].

\section{B. The Domestic Perspective}

There is relatively little literature that directly studies the effect of financial reporting quality on investment efficiency in China, but some scholars have begun to explore the relationship between them. Li Qingyuan (2009) uses the model of Richardson (2006) to measure the inefficient investment of the enterprises and shows that ceteris paribus, the quality of accounting information is negatively correlated with over-investment, especially in the company with high audit quality [11]. Xiang Kai (2009) shows that financial reporting could mitigate under-investment and overinvestment without considering financing constraints and cash surplus factors. His paper also shows in a state of financing constraints, the company's over-investment could be effectively suppressed by financial reporting through reducing agency costs, and in a state of cash surplus, the financial report failed to alleviate the lack of investment [12]. Zhou Song (2016) argues that high-quality financial reporting could reduce the lack of investment, but the effect of financial reporting on over-investment is not obvious [13].

\section{Limitations of Existing Literature}

On the basis of a lot of foreign and domestic literature, we can clear see that foreign research is more abundant than domestic in this regard. However, there are some limitations on this existing literature. First of all, the previous research on how to measure the quality of financial reporting is not perfect. That is to say, due to the rich content of financial report, any alternative variable can only reflect its meaning on the one side, which leads to the questioning of the reliability of these conclusions. Secondly, foreign research is more likely to take western mature capital market as prerequisite and developed countries (such as the United States) listed companies' data as samples. Considering the differences of capital market between China and developed countries, it is necessary to do more research to verify whether the previous research conclusions can be widely used in China. Thirdly, there is little literature to examine whether government intervention has an impact on the relationship between financial reporting quality and investment efficiency. In China, the government behavior plays an important role in the market resource allocation. For example, the government would like to help enterprises reduce the financing constraints to promote the economic development. Such behaviors would enhance the market competitiveness of enterprises, especially small and medium enterprises, but at the same time, they would weaken the degree of association between accounting information quality and investment efficiency. Furthermore, managers are more likely to be motivated to provide low-quality financial information for stakeholders with government intervention, which result in the deterioration of the principal-agent problem. Therefore, it is necessary to incorporate government behavior, financial report quality and investment efficiency into the same model to study whether the quality of financial reporting is related to the efficiency of enterprise investment.

\section{THE MECHANISM OF EFFECT OF FINANCIAL REPORTING QUALITY ON INVESTMENT EFFICIENCY}

\section{A. On the Basis of Principal-agent Theory}

Both Principal-agent theories are one of the main contract theories in institution economics, and the principalagent relationship is generated from the separation of ownership and control rights. Under the principal-agent relationship, there are two kinds of corporate governance problems, one is the issue between owners and agents, and the other is between major shareholders and minority shareholders. The former mainly due to inconsistent target interests and the information asymmetry between the stakeholders and the managers. That is to say, if the owners of the enterprise may not implement effective supervision, managers would use the internal information to pursue their own interests in the company's strategic decision. Bushman and Smith (2001) argue that the disclosure of accounting information could standardize the investment behavior of the company manager, mitigate the agency conflict, unify the objective function of the agent and the shareholder, and reduce the probability of the manager against the shareholders' interests[14]. Therefore, high-quality financial 
accounting information can improve the efficiency of investment by strengthening supervision, improving incentives and perfecting contracts. Demsetz (1983) found that in emerging Asian countries, the more prominent problem is the second type [15]. As the major shareholders of the modern company having advantages of stock and control rights, they are more convenient to use their own position to damage the interests of minority shareholders through tunnel digging. For this issue, with resort to the disclosure of real information such as the company's financial condition, operating conditions and cash flow, high-quality financial reporting can not only reduce agency costs, but also reduce the financing friction caused by incomplete contracts, thus improve the company's investment efficiency.

\section{B. On the Basis of Information Asymmetry Theory}

Akerlof (1970) first thoroughly analyzed moral hazard and adverse selection of information asymmetry problems. Adverse selection comes from information asymmetry before decision [16]. In this model, if a manager with more information sells over-priced securities and obtains large amount of capital, he is very likely to over invest. To avoid the loss caused by information asymmetry, capital providers may ration the capital they provide, or raise the cost of managers obtaining capital. This kind of information asymmetry causes financing constraint and even credit rationing. To lower financing costs, a company may give up positive NPV projects, which then causes insufficient investment. Based on the pricing function of accounting information, high quality financial statements can effectively reflect the operation situation of a company and help investors to reasonably assess the value and return ratio of a company's securities, thus promoting capital flows, reducing adverse selection and increasing investment returns.

Moral hazard comes from information asymmetry post decision. In this model, a manager invests according to the resources the company can get, which may lead to over investment or insufficient investment. On one hand, if a company has surplus resources, due to information asymmetry, the manager may pursue his own interests and indulge in excessive on-the-job consumption, which causes over investment. On the other hand, investors may be aware of the self-interested behavior of managers, so investors may constrain the manager's authorities, or ration the capital of the company's investment activities, which then causes insufficient investment. High quality financial information can provide company performance, investment efficiency and other important information for investors, thus increasing communication efficiency between companies and investors, supervising and guiding managers to choose the right investment strategies and mitigating the inefficient investment problems caused by information asymmetry.

\section{CONCLUSION}

A lot of domestic and foreign literature indicate that the high-quality financial reporting can restraint the selfinterested behaviors of managers, improve the transparency of enterprise information, help investors to judge the enterprise value and relieve the inefficient investment caused by principal-agent relationship and information asymmetry as well. Therefore, it is necessary to take effective measure to improve the quality of financial reports, and then raise the efficiency of enterprises investment.

First of all, governments should accelerate the improvement of enterprise information disclosure system and standardize the information disclosure behavior to play the regulative role of laws and regulations. Accounting information is an important pathway that investors understand the status of business management and make decisions on resource allocation. On the contrary, either managers disclose excessive useless information, or conceal major information, or issue non-standard financial reports. These actions are bound to get in the way to make effective and correct investment decisions for investors. Therefore, it is important to standardize the information disclosure behavior of managers, improve the relevance, reliability and comprehensibility of accounting information, and promote the punishment of nonstandard financial reports, in turn, improve the quality of financial reports and improve the efficiency of enterprise investment.

Secondly, Corporations should regulate the accounting behavior of the financial department, ensure the timeliness, intelligibility and reliability of accounting information, and issue a truthful and credible financial report. Next, the role of the board of directors and the board of supervisors should be played. If necessary, the audit committee and the risk control committee may be set up to supervise the operation of the enterprise financial system. What's more, corporations should improve the management incentive mechanism, such as adopting measures of equity incentives and annual salary system to reduce the self-interest behavior of managers' layer, and then make the management of personal interests in accordance with the goal of interests of investors.

Thirdly, related departments should accelerate the examination and approval system reform, streamline administration and delegate power to the lower levels, reduce the financing constraints and raise the efficiency of investment for those medium and small enterprises which have the bright development prospect. Meanwhile, it is necessary to actively perform the government regulation, adopt workable government funds application, cooperate with the external audit to increase the quality of financial reports, in turn, help investors to make effective investment decisions.

\section{REFERENCES}

[1] Patricia M. Dechow, Ilia D. Dichev, "The Quality of Accruals and Earnings: The Role of Accrual Estimation Errors, " The Accounting Review, vol. 77, pp. 35-39, 2002.

[2] Peng Shaobin, Huang Yijian, Zhao Gen, "Information Reliability, Corporate Growth and Earnings Resistence, "Accounting Research, vol. 3, pp. 43-50, 2008.

[3] Zhou Zhongsheng, Chen Hanwen, "Accounting Information Transparency and Resource Allocation Efficiency," Accounting Research, vol. 12, pp. 56-62, 2008. 
[4] Vogt S, "The Cash Flow/Investment Relationship Evidence from U. S. Manufacturing Firms , "Finncial Management, vol. 23, pp. 320, 1994.

[5] Scott Richardson, "Over-investment of free cash flow, "Review of Accounting Studies, vol. 11, pp. 159-189, 2006.

[6] Wei Haiming, Liu Jianhuau“Soe Dividend, Governance Factor and Over-Investment” Management World, vol. 4, pp. 88-95, 2007.

[7] Xin Qingquan, LI Bin, Wang Yanchao, "Government Control, Executive Compensation and Capital Investment" Economic Research Journal, vol. 8, pp. 110-122, 2007.

[8] Rodrigo S. Verdi, "Financial Reporting Quality and Investment Efficiency" Working Paper, University of Pennsylvania, 2006.

[9] Biddle G, Gilles Hilary, "Accounting Quality and Firm-Level Capital Investment. ," The Accounting Review , vol. 81, pp. 963-982, 2006

[10] Cutillas Gomariz, M, Sánchez Ballesta, "Financial Reporting Quality, Debt Maturity and Investment Efficiency, "Journal of Banking and Finance, vol. 40, pp. 494-507, 2014.

[11] Li Qingyuan, "Accounting Information Quality, Auditing Monitoring and Corporate Investment efficiency-Empirical evidence of our listed corporations, "Auditing Research, vol. 4, pp. 65-73, 2009.

[12] Xiang Kai, "Financial Reporting Quality and Corporate Investment Efficiency, "Journal of Zhongnan University of Economics and Law, vol. 2, pp. 62-68, 2009.

[13] Zhou Song, "Analyse and Summarize on The Effect of Financial Reporting Quality on Investment Efficiency, " Contemporary Accounting, vol. 3, pp. 03, 2016.

[14] Robert M. Bushmana, Abbie J. Smith, "Financial information and corporate governance," Journal of Accounting and Economics, vol. 32, pp. 237-333. 2001.

[15] Demsetz. H, "The Structure of Ownership and the Theory of the Firm, " Journal of Law and Economics, vol. 26, pp. 375-390, 1983.

[16] George A.

"The A Market for Lemons: Quality Uncertainty and Aker Market Mechanism, "The Quarterly Journal of Economics, vol. 84, pp. 488-500, 1970 